\title{
La fachada barroca del templo de Santo Domingo de San Cristóbal de las Casas (México) y su reintegración pictórica: una intervención polémica
}

\author{
Haydeé Orea Magaña
}

\section{Introducción}

\begin{abstract}
- I templo de Santo Domingo en San Cristóbal de las Casas (Chiapas, - México), como lo conocemos hoy en día, fue terminado en 1698. ${ }^{1}$ Su - fachada-retablo es "un alarde de expresión plástica barroca gracias al delicado trabajo de relieve que muestra en toda [la superficie de la portada...] y es que el estuco coloreado, como material de acabado, es uno de los elementos característicos de la arquitectura sancristobalense" (Artigas H. 1997:48). La portada, considerada como la manifestación más importante de la plástica en la arquitectura construida por los dominicos en Chiapas, se orienta hacia el lado poniente del templo y sus medidas generales son $24 \mathrm{~m}$ de alto por $18.5 \mathrm{~m}$ de ancho. Para entender con mayor facilidad la estructura en la composición arquitectónica del retablo, lo dividimos en tres calles y tres cuerpos, de la siguiente forma (Figura 1).
\end{abstract}

Las tres calles que componen el eje vertical de la fachada están divididas entre sí por juegos de columnas pareadas, y los diferentes niveles horizontales, por juegos de cornisas de gran relieve, compuestos, en general, por arquitrabe, friso y cornisa en diferentes proporciones, según el nivel al que corresponden. A los extremos laterales de la superficie de la fachada, decorada con relieves, se encuentran los paramentos lisos de las torres que soportan los campanarios, los cuales equilibran el conjunto (López Bravo 2000:15) (Figura 2).

La advocación central, y principal, de esta fachada-retablo es a santo Domingo de Guzmán y sus santos predicadores. ${ }^{2}$

\footnotetext{
${ }^{1}$ Según el testimonio del padre Joaquín Antonio de Villalobos, quien se refirió a la iglesia como "de las mayores de la ciudad" y al convento como "suntuoso" (Artigas H. 1997).

${ }^{2}$ Están representados, muy probablemente, los santos Pedro Mártir y Jacinto de Polonia; Daniel entre los leones; el monograma IHS, que se interpreta como "Jesús, salvador de los hombres"; los santos Vicente Ferrer, Tomás de Aquino, Catalina de Siena, Rosa de Lima y Catalina Mártir; representaciones de águilas; custodias flanqueadas por ángeles sahumadores; águilas bicéfalas coronadas, emblema de los Asturias, y sirenas, entre otros personajes míticos (Aubry 1991:165;
} 


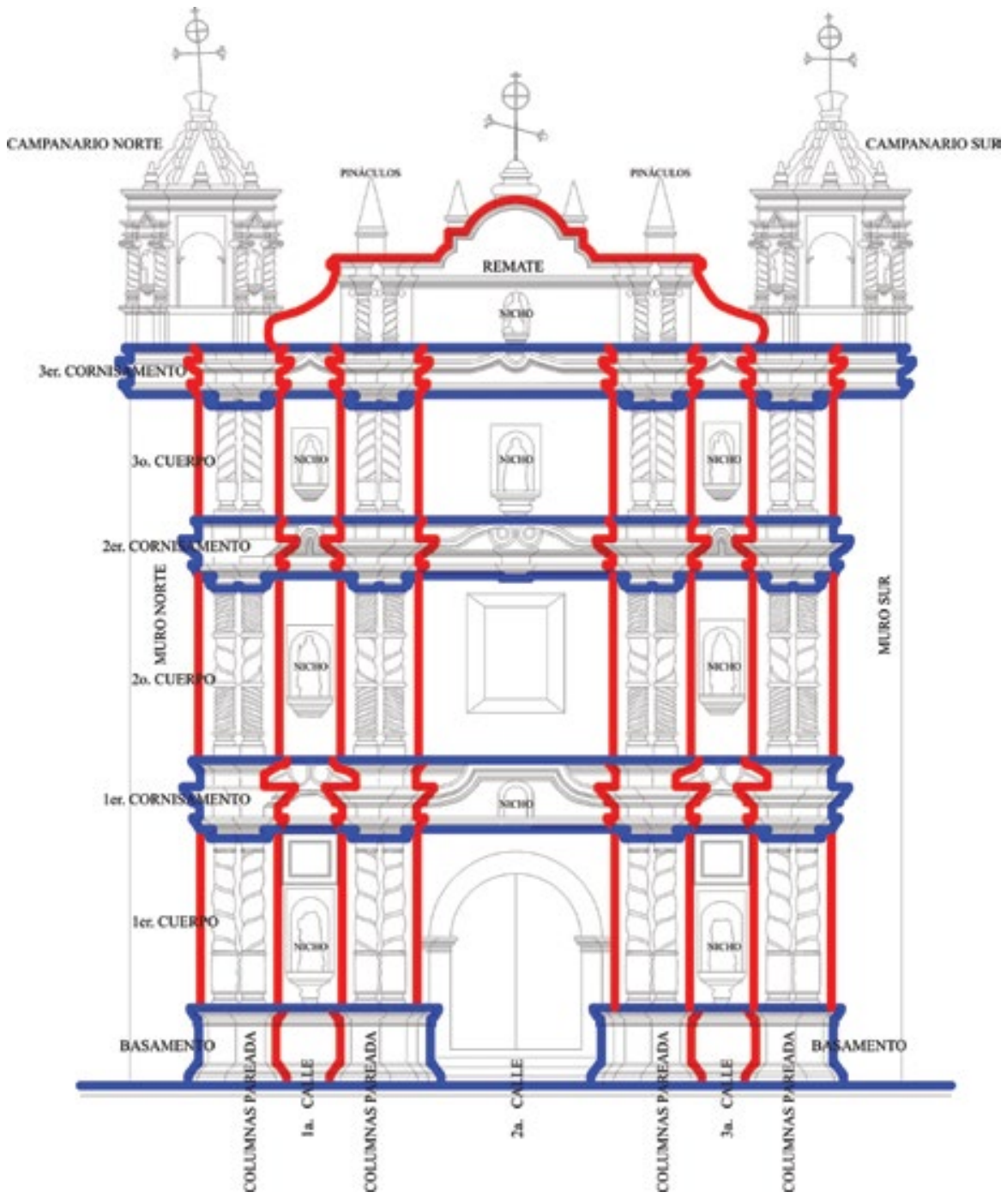

FIGURA 1. Distribución de calles y cuerpos en la fachada (Dibujo: J. Hernández; fuente: Orea Magaña 2007).

\section{Reflexiones en torno del proceso de reintegración de la fachada}

Los teóricos de la restauración han propuesto teorías filosóficas y principios enfocados primordialmente en la restauración de los monumentos arquitectónicos, cuya traducción al campo de la restauración de los acabados arquitectónicos o, en este caso concreto, a decoraciones en relieve policromadas, conlleva grandes dificultades.

Monterrosa Prado 1979:138; comunicación personal del presbítero Pablo Iribarrén y del padre Roberto Álvarez 2006). en los años setenta del siglo Xx. Llevada a cabo por el arquitecto Vicente Guerrero, se centró en su consolidación y estabilización estructural, ya que la parte central se encontraba en peligro de colapso. Gracias a dichos trabajos, nuestra intervención en 2006 pudo abocarse a la limpieza, resane, restitución y corrección de elementos arquitectónicos dañados, como las cornisas y cubiertas, y, finalmente, a la realización de calas y la reintegración de color, tema de la presente disertación.

Las calas estratigráficas, efectuadas con la finalidad de conocer a la perfección la compleja superposición de capas pictóricas que presentaban los relieves, revelaron, en un bien tan extenso como la fachada de Santo Domingo, expuesto a condiciones de intemperismo: Iluvia, escurrimientos, viento, etc., una diversidad de información acerca de las capas de pintura directamente relacionadas con los procesos de alteración que incidían en mayor o en menor grado en cada una de sus secciones.

Fue así como en la parte superior de la fachada, donde se daban los mayores escurrimientos, no se encontraron sino pequeños restos de color en recovecos y zonas menos expuestas a la intemperie, en tanto que en el cuerpo inferior se hallaron hasta cinco capas pictóricas preservadas, gracias a las cornisas de los cuerpos superiores, que desviaban el agua e impedían su deterioro. Éstas corresponden con sendos momentos en la historia de la fachada, en los que, por motivos estilísticos, o con el fin de darle mantenimiento, se cubrió la primera policromía ${ }^{3}$ (Figura 3).

Se estimó que la primera capa pictórica encontrada fue la más antigua, ya que debajo de ella se halló una más, muy fina, de enlucido de cal y arena sin color, que seguramente sirvió únicamente como ción de color de la manera como la hicimos, detallo a continuación las circunstancias que la precedieron:

La intervención más reciente de la fachada de Santo Domingo sucedió
${ }^{3} \mathrm{Al}$ menos tres de esos momentos pictóricos se han asociado con acontecimientos históricos documentados. 


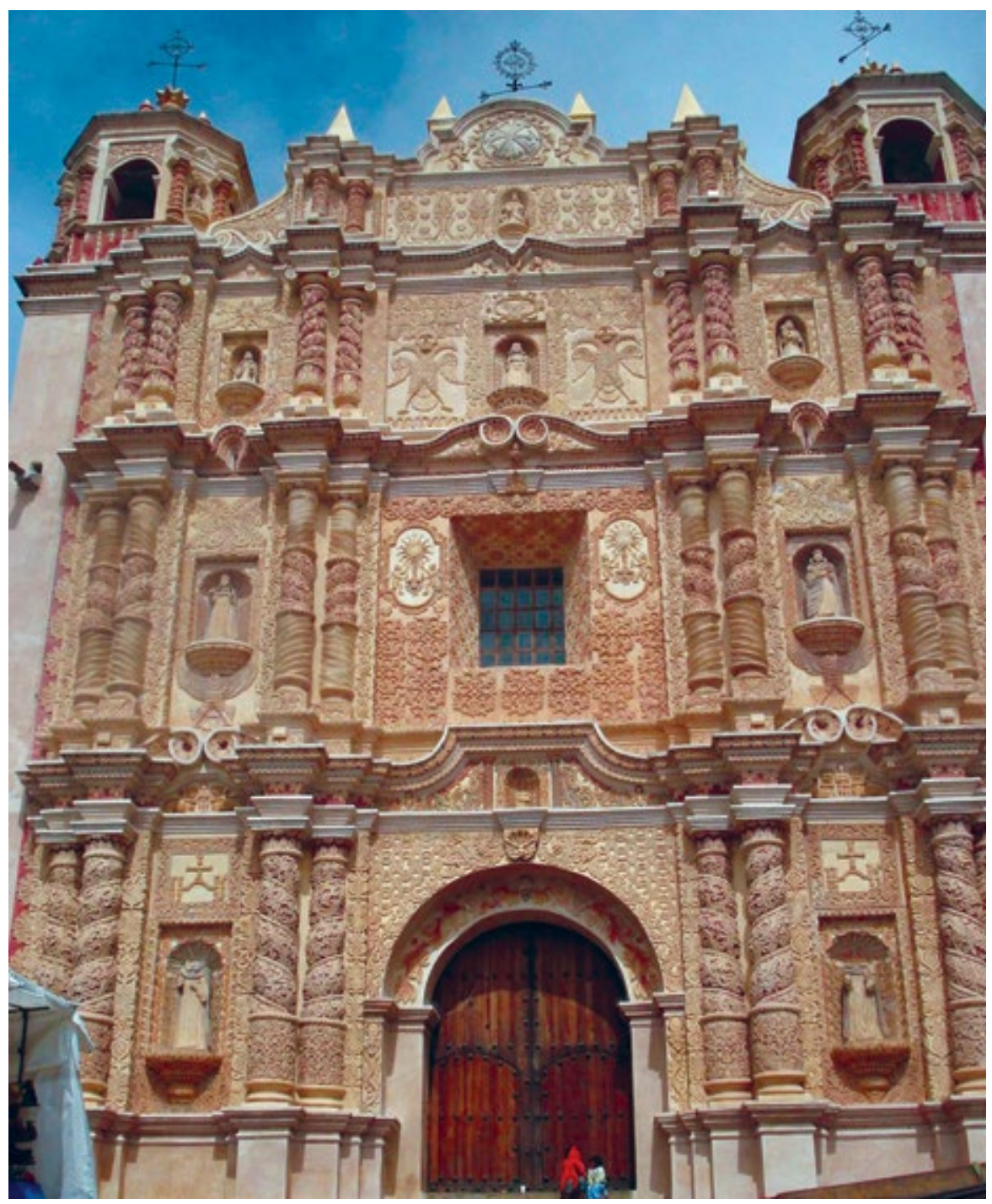

FIGURA 2. Fachada de Santo Domingo después de su restauración (Fotografía: Haydeé Orea, febrero del 2007).

base de preparación para la aplicación de la primera policromía. Ésta empleó pigmentos terrosos principalmente para lograr su esquema pictórico, cuyo fin consistió en realzar los relieves a través de la intensificación de sombras y luces y la creación de claroscuros. Encontrar tal riqueza pictórica fue un suceso del todo inesperado para los restauradores y, mayormente, para los historiadores $y$ arquitectos que han descrito esta portada en proyectos, informes y diversas publicaciones. ${ }^{4}$

4 Entre ellos, el historiador Andrés Aubry (1990), el doctor Juan Benito Artigas H. (1984 y 1991), el historiador Julio Domínguez y los
Aunque algunos autores, como Markman (1984), argumentan que las modas estilísticas no siempre llegaron a Chiapas en la misma época de su auge en Europa o en la ciudad de México, capital del virreinato, el tratamiento pictórico dado a la fachada en la primera y la segunda capas corresponde con el estilo barroco, también reflejado en el aplicado en los retablos del interior del templo, datados estilísticamente hacia la misma época.

Es posible que el autor anónimo del proyecto para esta fachada haya

arquitectos Vicente Guerrero, Álvaro de la Cruz López Bravo y Gerardo Mendiguchía. provenido de Europa (posiblemente, un clérigo dominico español) o, si fuese novohispano, haya viajado a España, pues es notorio que estaba al tanto del nuevo movimiento artístico del momento: el barroco. La primera policromía de aquélla acentuaba cada elemento decorativo y personaje presentes y los delimitaba claramente para hacerlos comprensible al espectador.

La segunda capa es un enigma, pues no se encuentra en todos los elementos de la fachada, sino sólo en partes muy concretas. Podría tratarse de una capa de mantenimiento de la primera, muy parecida a ésta en algunos puntos y muy distinta en otros, ${ }^{5}$ aplicada para retocar algunos daños poco tiempo después de haberse realizado la policromía original. El autor y la técnica de esta segunda capa difieren claramente de los de la primera, puesto que son distintos el tratamiento, la brillantez y la forma de realizar los motivos, aunque no se modifica la iconografía de la primera.

La tercera capa ha sido denominada como neoclásica, ${ }^{6}$ en tanto que emplea una gama de tonos más claros y una paleta limitada, basada, esencialmente, en el uso de un color crema que da a los relieves un tono menos intenso; de ahí que se estime que su realización fue durante el siglo XIX. Posteriormente se aplicaron dos capas más de pintura, en las que, además de que la gama de colores se redujo a dos: amarillo y naranja, se uniformaron las superficies, al extender estos colores sobre grandes áreas, restándoles variedad y, por ende, la posibilidad de observar su riqueza de elementos y tratamientos. Es muy probable que estas

\footnotetext{
${ }^{5}$ En pequeñas secciones del friso que se encuentra en el primer cornisamento, y en los nichos del cuerpo inferior de la portada, se empleó un color verde identificado, para nuestra sorpresa, como malaquita.

${ }^{6}$ Denominación dada por los restauradores responsables de la ejecución de la obra, María Elena Fernández Santoyo y Constantino Armendáriz Ballesteros.
} 


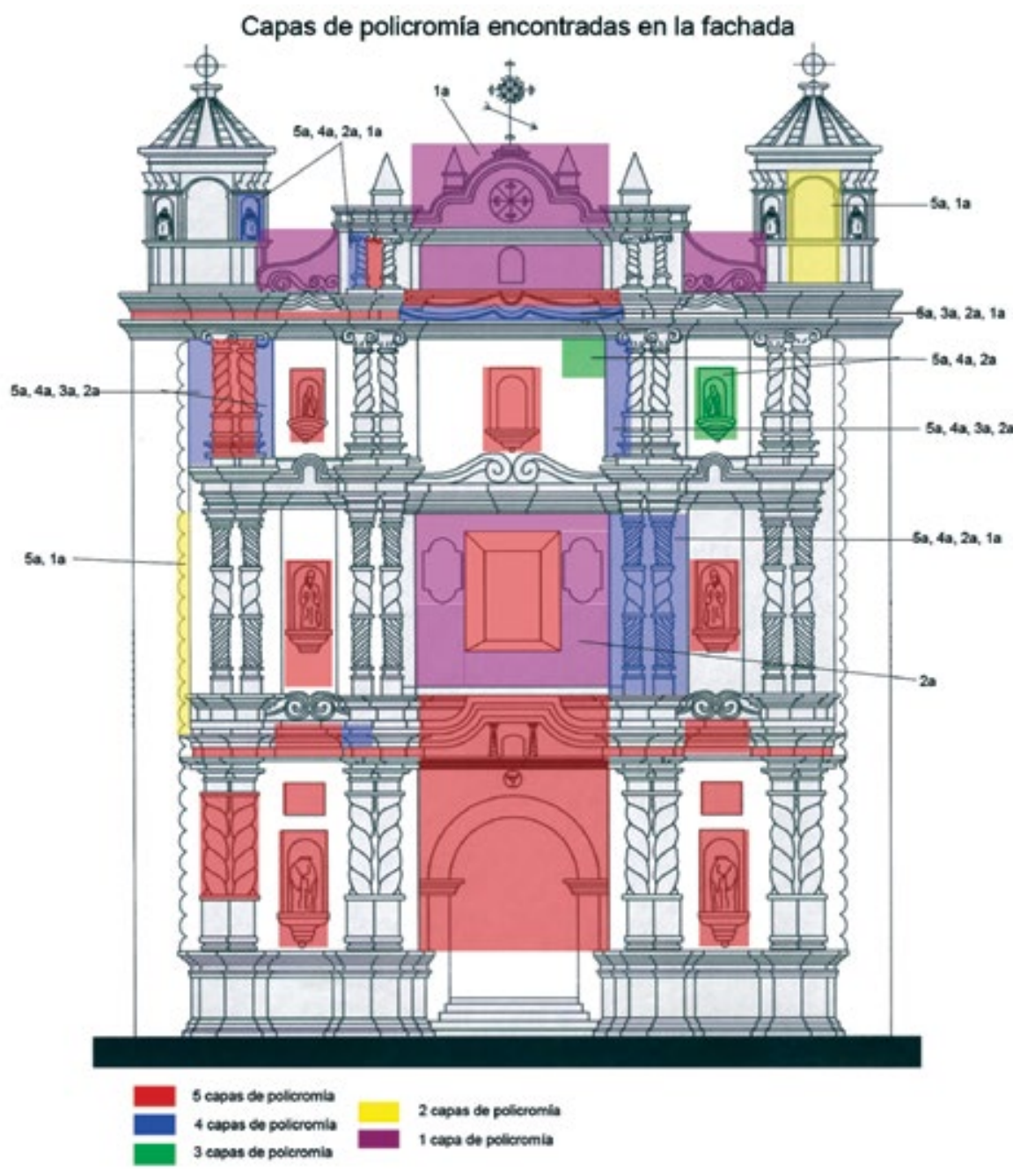

FIGURA 3. Capas de color encontradas en la fachada (Fuente: Orea Magaña 2007).

dos capas se hayan aplicado en el siglo Xx. Después de efectuar 157 calas de $40 \times 35 \mathrm{~cm}$ (con unas de menor tamaño no se conseguía suficiente información, dada la extensa superficie de la fachada), fue evidente que las capas pictóricas mejor conservadas y que más datos proporcionaban sobre el aspecto más antiguo y más rico pictóricamente que esta fachada pudo presentar eran la primera $y$, apenas en ciertas zonas, la segunda (Figura 3).

Como el proyecto de intervención de la fachada contaba con un plazo y presupuesto limitados desde su origen, no se creyó factible llevar a cabo la "eliminación" de las tres capas de pintura subsecuentes para descubrir la primera o la segunda: el grado de dificultad y la duración que implicaría este proceso se evidenció durante la ejecución de las calas, ya que en muchos casos se tuvo que recurrir a medios químicos (solventes, vapor de agua), además de los mecánicos, y el resultado no siempre era del todo satisfactorio. Retirar las capas subsecuentes a la original, muchas veces fuertemente adheridas a ésta, exigía arrancarla o dañarla.

De haberse considerado esa posibilidad, cuyo objeto habría consistido en conservar la pintura original lo más intacta posible, el proyecto hubiese demorado varios años antes de descubrirla. Pero también existían otras consideraciones teóricas, además del tiempo y el presupuesto, para no realizar esta acción. Es aquí donde afrontamos la dificultad de interpretar los conceptos teóricos concebidos para la intervención de monumentos arquitectónicos y, más aún, de aplicarlos en sus decoraciones o acabados.

En su artículo 11, la "Carta de Venecia" dice: "Las aportaciones válidas de todas las épocas en la edificación de un monumento deben respetarse, ya que la unidad de estilo no es un fin por alcanzar en el curso de una restauración" (Díaz-Berrio 1968:24). El artículo se refiere a etapas constructivas y a liberaciones, ${ }^{7}$ que

[...] no se justifican más que excepcionalmente, y a condición de que los elementos eliminados no presenten más que poco interés, que la composición traída a la luz constituya un testimonio de alto valor histórico, arqueológico o estético y que su estado de conservación sea considerado suficiente (Díaz-Berrio 1968:24-25).

En apego al segundo principio de la restauración, que dice que "la restauración debe lograr el restablecimiento de la unidad potencial de la obra de arte, mientras sea posible alcanzarlo sin cometer una falsificación artística ni una falsificación histórica y sin borrar las huellas del paso de la obra a través del tiempo"; que "el problema esencial, según la instancia histórica, consiste en la conservación o la supresión de los agregados", y que un agregado "no es más que un nuevo testimonio del hacer humano y del tránsito de la obra de arte en el tiempo [...] y posee los mismos derechos de ser conservado" (Brandi 1990:9), la decisión correcta era conservar al menos las tres primeras policromías de los relieves, pues, de haber eliminado alguna de las capas, se hubiese destruido un

\footnotetext{
${ }^{7}$ A pesar de que la palabra liberación y lo que implica en una etapa o elemento constructivo no es del todo equivalente al retiro de una capa de pintura.
} 
documento, amén de que "la conservación de los agregados debe ser la norma y la remoción será la excepción" (Brandi 1990:47). En el caso de las dos últimas capas pictóricas presentes en la fachada, sin embargo, sí hubiese aplicado lo siguiente:

[...] la supresión del agregado no puede ser tajante, más que en el caso de adiciones que se hayan perpetrado sin una reelaboración del conjunto del texto pictórico, escultórico, arquitectónico y aparezcan como intrusiones irrespetuosas hacia el monumento (Brandi 1990:47).

Todo lo anterior nos planteaba un dilema: por un lado, como ya se mencionó, aunque se hubiera previsto la posibilidad de remover las capas pictóricas que precedieron a la tercera, no hubiéramos contado con el tiempo para hacerlo; por el otro, los agregados compuestos por la última y la penúltima capas no eran, al parecer del equipo, valiosas desde el punto de vista estético: impedían la clara apreciación del conjunto en su totalidad, y borraban y mimetizaban, en un tono grosero, la multiplicidad de detalles y formas, de tal manera que eliminarlos se hubiese juzgado como un proceso factible, es decir, con su destrucción no se perdería un dato de carácter estético valioso, aunque sí uno de tipo histórico: el que nos habla de las épocas en las que se le dio a la fachada, si bien burdamente, mantenimiento.

No obstante, eliminar la tercera capa, de colores claros, que subrayaba de manera sutil las decoraciones de la fachada, hubiese representado un hecho cuya legitimidad difícilmente se justificaría en términos de la restauración del conjunto.

Dicha capa ofrece, tanto estética como históricamente, valiosa información: da a conocer los cambios de color y tono que el elemento decorativo sufrió dados los nuevos estilos o modas imperantes en épocas posteriores (siglo XIX) a la realización de la primera policromía, y, aunque no se encontró presente en todas las áreas,

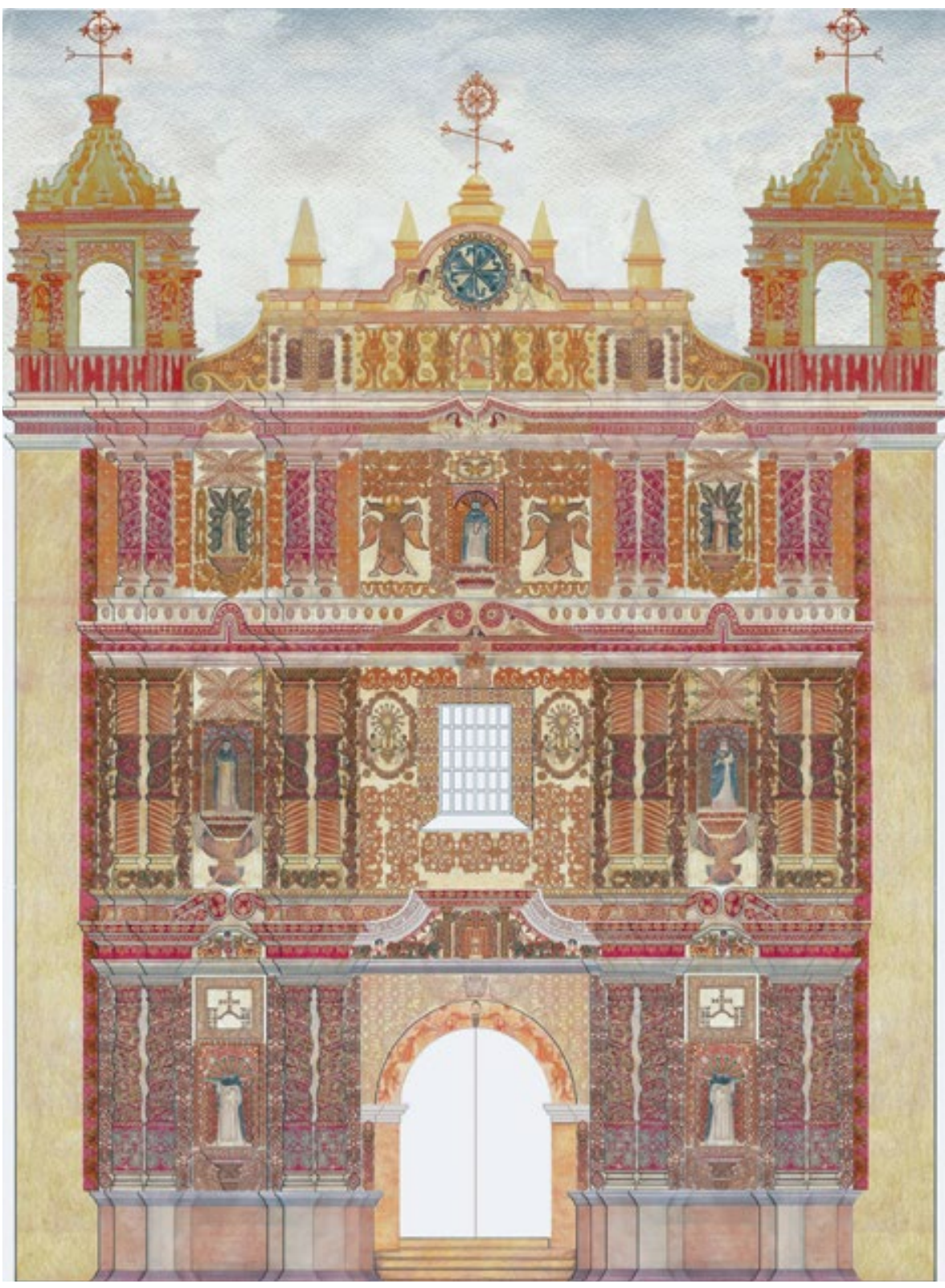

FIGURA 4. Propuesta de color para la fachada con base en la información obtenida de las capas pictóricas uno y dos, observada en las calas estratigráficas (Dibujo: Jorge B. Hernández Aguilar y J. Constantino Armendáriz Ballesteros; fuente: Orea Magaña 2007).

enfatizaba de manera más suave los elementos decorativos, dotándolos de una calidad estética diferente de la que se manejaba en la primera y la segunda capas pictóricas. ¿Qué hacer entonces con el aspecto que presentaba la fachada, que dejaba bastante que desear en términos de presentación ${ }^{8}$ tras haber concluido

${ }^{8}$ Para ese momento de la intervención, la fachada sólo presentaba en su aspecto general dos colores: el amarillo y el naranja, así como los procesos de consolidación y estabilización, y, más todavía, después de haber encontrado la riqueza de información sobre su tratamiento pictórico? (Figura 5).

Fue entonces, ante la evidencia encontrada en las calas, cuando se optó por la decisión de conservar todas las capas encontradas, cubriéndolas, y presentarlas de acuerdo con

una infinidad de recuadros, correspondientes a las calas. 


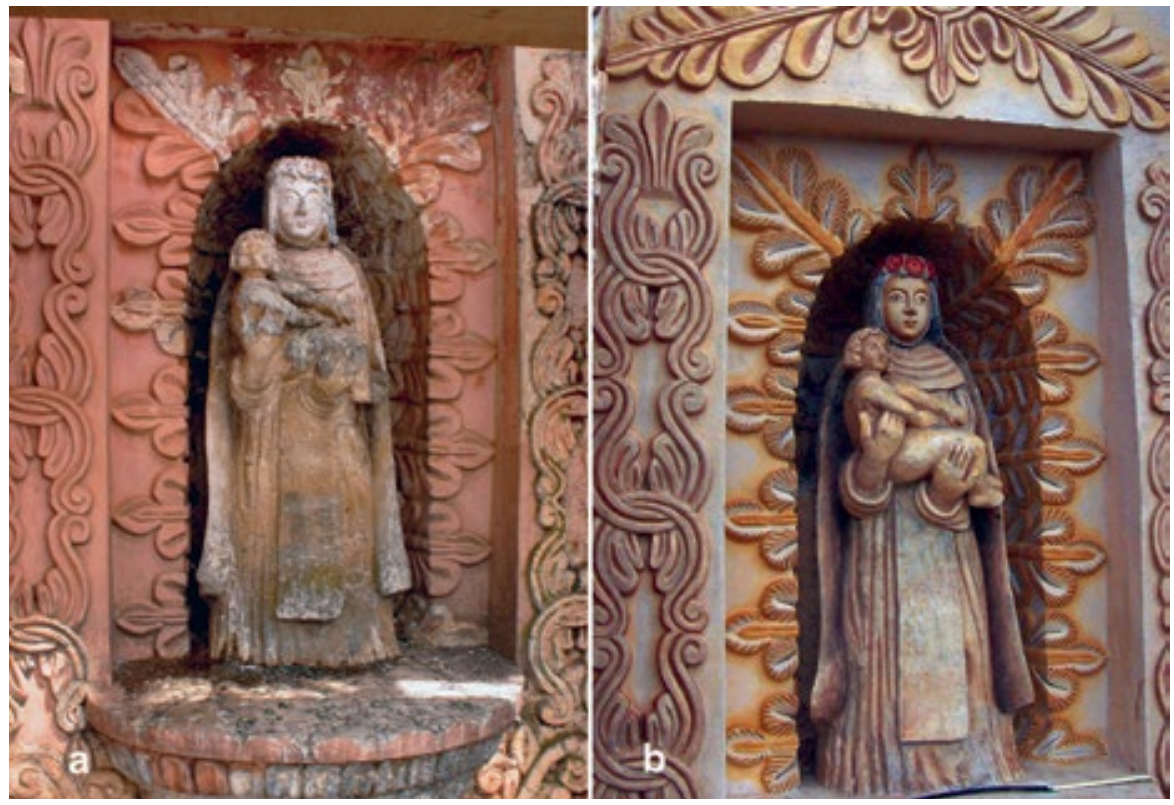

FIGURA 5. Santa Rosa de Lima antes (a) y después (b) de la restauración (Fotografías: a) María Elena Fernández Santoyo, b) Haydeé Orea; fuente: Orea Magaña y Fernández Santoyo 2006).

la información obtenida en la primera y la segunda. De este modo, se retiraron las escamas de la última y la antepenúltima capas de pintura, si y sólo si, se encontraban semidesprendidas, ya que, estimamos, el tiempo que hubiésemos tenido que dedicar a su fijado era excesivo y no contábamos con él.

Esta decisión se fundaba en los principios de la conservación, los cuales señalan que "se prescribe que toda intervención de restauración no debe hacer imposibles, sino posibles, las eventuales intervenciones futuras" (Brandi 1990:28). Al conservar las diversas capas pictóricas debajo de la capa de color aplicada para dar la reintegración, hacíamos posible que, en un futuro, otros restauradores con el tiempo y la tecnología adecuados, si así lo decidían, liberaran las capas de pintura más antiguas de la fachada. Para ello los restauradores desarrollaron en papel las "propuestas" de reintegración de los relieves o personajes, coloreando los alzados que el arquitecto realizó ${ }^{9}$, ya por sec-

${ }^{9}$ El alzado de todos los relieves de la fachada a escala 1:1 fue realizado por el arquitecto Jorge B. Hernández Aguilar a solicitud de la reatauradora Haydeé Orea, ya que no existía tores, ya por áreas, de acuerdo con los datos obtenidos de las calas. Lo anterior debe asentarse en razón de que para que el equipo llegara a la comprensión de cómo se usó el color en cada momento y de la forma en que se lograron los acabados y estilos en cada época, se tomó una enorme cantidad de tiempo en el registro gráfico y la apreciación de las diversas capas pictóricas, información con la que se conformó un esquema general de color de toda la fachada para la primera y la segunda capas pictóricas con base en el cual trabajar la reintegración (Figura 4).

¿Por qué se tomó la resolución de que fuesen estas dos capas las elegidas para la reintegración de color y no la tercera? Porque eran las que presentaban mayor variedad de juegos de color, de luz y sombra, y de detalles pictóricos, y porque se encontraban evidencias de ellas en casi toda la superficie de la portada, en tanto que en lo que toca al aspecto de la tercera había grandes lagunas en diversas secciones de la decoración. Además, al recobrar la apariencia de la fachada en su primer $y$ hasta entonces. un documento que registrase su complejidad segundo momentos, se recuperaba, desde nuestro punto de vista, el momento más brillante y más destacado en términos plásticos de su decoración pictórica.

Se realizaron ensayos para identificar la paleta empleada en estas dos primeras capas pictóricas, con el fin de imitarla en sus diversos tonos, y se estudió y determinó la técnica empleada para la elaboración de los relieves y elementos escultóricos de la fachada. ${ }^{10}$

De acuerdo con el grado de conservación que presentaban las superficies decoradas, éstas se trataron de diversas formas:

1. En ocasiones, cuando se encontraba completa, se dejó expuesta la primera capa pictórica, y sólo se resanaron y reintegraron los pequeños faltantes que presentaba.

2. Cuando la primera capa estaba en malas condiciones, se expuso a la vista la segunda.

3. En la mayoría de los casos, se cubrieron los relieves — que podían presentar una, dos, tres, cuatro o cinco capas de pintura- con una capa de enlucido fino de cal, talco de mármol y color, con el propósito de darle un tono ligeramente beige, semejante al del original. Sobre esta capa, que uniformizaba las superficies, se aplicaron los colores en tintas y se patinaron.

Para realizar la reintegración se eligió la técnica del temple de caseína, puesto que, de acuerdo con las pruebas realizadas, era lo suficientemente resistente como para aglutinar el color y mantenerse a la intemperie. ${ }^{11}$ Efectuar este trabajo al fresco

\footnotetext{
${ }^{10}$ Se efectuaron cortes estratigráficos, análisis de microscopia electrónica de barrido (SEMEDX) y tinciones. Si bien no se logró identificar los aglutinantes empleados, se considera, por la solubilidad y el aspecto a simple vista de la pintura, así como por su técnica (en la que se aprecian superposiciones de color) y por su deterioro, que la fachada se pintó al temple.

${ }^{11}$ La caseína se usó en proporciones muy bajas, diluida en agua, con el objeto de que no
} 
hubiese sido lo ideal en términos de su preservación a largo plazo, pero lo hicieron inviable el tiempo y la capacitación demandados para su ejecución. Como nos preocupaba en grado sumo que la fachada presentase una apariencia "nueva", como de obra recién realizada, también se discutió ampliamente el tipo de acabado que se deseaba obtener en la reintegración de color. A pesar del hecho de que este procedimiento confrontará al espectador con el aspecto que la fachada pudo presentar hace al menos 150 años y que las capas de pintura posteriores habían ocultado, no deseábamos que tal efecto fuese chocante y apabullante para quienes la conocieron antes de la intervención. De ahí que todas las superficies se colorearan en tonos más sutiles que los que presentaba el original, y se "patinaran" con una mezcla de colores que les daban un aspecto ligeramente envejecido. ${ }^{12}$

No obstante que como grupo de trabajo teníamos la certeza de haber tomado las decisiones pertinentes para realizar el proceso de reintegración de color, muchas veces nos preguntamos si como conservadores estábamos en lo correcto en Ilamar a

se formaran capas de color gruesas que se desprendieran con facilidad. Las aguadas de color se superponían unas a otras hasta alcanzar el tono deseado, de forma que se controlaba de manera muy cuidadosa su intensidad y se lograba dar las calidades de textura y brillantez, semejantes a las del original envejecido, apreciables en las calas. Los tratados para la ejecución de pintura mural señalan reiteradamente que la pintura al temple de caseína está entre las técnicas pictóricas más resistentes a la intemperie, siempre detrás del fresco (Doerner 1989:194-195).

12 Se retomaron experiencias como la de la restauración de la policromía en la iglesia de Santa Rosa de Viterbo (Querétaro, México), en la que, como en nuestro caso, los restauradores contaban con información suficiente sobre la decoración de las superficies arquitectónicas, lo que permitió "recuperar esta rica decoración en su totalidad [...] ya que se usaron los mismos pigmentos presentes en la obra antigua, pero en saturaciones menores que en el siglo XVII, para respetar la historicidad del edificio" (Wrigth Carr 1988:159-159). este trabajo una reintegración de color o debíamos definirlo como una recreación —voz que no se ha empleado ni está definida en la terminología empleada en la conservación o restauración de bienes inmuebles o muebles-. Y si esto último fuese cierto, ¿nuestro trabajo seguía siendo una restauración o podía incluso considerarse una falsificación?

Creemos que las diversas definiciones sobre lo que es o no la restauración, sus objetivos, sus alcances sus métodos, acreditan o descalifican, según como queramos leerlas, nuestro proceder: Jokilehto (2004) habla de los propósitos de la restauración más allá de mantener materialmente el bien y menciona que uno de éstos es el de facilitar su interpretación; Brandi, de "volver a poner en funcionamiento (rimettere in efficienza) algún producto de la actividad humana" (1990:7). Las siguientes definiciones abogarían por nuestra decisión:

La conservación y la restauración de los monumentos tienen como objetivo salvaguardar tanto la obra de arte como el testimonio histórico. [...] Se detiene allí donde empieza la hipótesis [...]. La intervención de restauración destinada a restablecer la unidad original, desarrollando la unidad potencial inmanente en los fragmentos, sólo debe limitarse al desarrollo de las sugerencias implícitas en los mismos fragmentos o en testimonios auténticos del estado original de la obra (Díaz-Berrio 1968:13-27).

"Para llegar a ser una operación legítima, la restauración no deberá pretender ni la reversibilidad del tiempo ni la abolición de la historia" (Brandi 1990:36), y se señala que la propia restauración forma parte de los sucesos históricos del bien, y debe diferenciarse.

En la reintegración de la fachada tal diferenciación se marcó a través del seguimiento de la técnica original, pero aplicando los colores en intensidades más tenues, y a través de un extenso trabajo de documentación gráfica y fotográfica. ${ }^{13}$

Respecto de la falsificación, Brandi comenta que la diferencia entre falsificar, copiar e imitar está en la intencionalidad con la que se hace y no en los medios que se emplean para ello, de acuerdo con lo cual nuestro trabajo sería una copia, en razón de que se produce "un objeto a semejanza o como reproducción de otro objeto, tanto en formas como en estilo de un periodo determinado, o de una determinada personalidad artística, con el único fin de documentar el objeto del placer que ello pueda producir", y no una falsificación, puesto que no tiene la intención de engañar "ni de hacerlo pasar por una obra auténtica". "[La copia es] el proceso de producción de una obra singular o de reproducción de formas, ya sea de un estilo propio de una época o de un autor determinado" (Brandi 1990:87).

Finalmente, una de las justificaciones para llegar a considerar la aplicación de capas de estuco y color sobre los restos de las policromías presentes en los relieves fue que éstas, en la medida en que funcionarían como un acabado de "sacrificio" que retardaría su degradación, ayudarían a protegerlas:

Revestir los muros pétreos y otros elementos con diferentes tipos de recubrimientos [fue una práctica casi universal]. En la Nueva España era usual aplanar los elementos pétreos con mortero de cal y arena [...] se aplicaban finos enlucidos de cal, en la forma de aplanados del-

13 Coincidimos de nuevo con el criterio de Wrigth Carr (1988:162-163), quien señala que "En los monumentos donde sólo hay escasos restos de los recubrimientos originales sobre los elementos de piedra labrada, se podría tomar el dato de los colores existentes, para aplicar capas protectivas uniformes [...] se podría aplicar una capa protectora de lechada de cal viva, con otra mano de pintura [...], usando el mismo pigmento encontrado en los vestigios originales. Aplicar los colores en saturaciones más bajas ayudaría a conservar el aspecto 'antiguo' del monumento [...]". 
gados, o bien lechadas de cal. [...] La capa final tenía la función, especialmente en exteriores, de proteger la piedra de los deterioros causados por agentes ambientales nocivos (Wrigth Carr 1988:144-148).

Así, lo efectuado promovería la protección de los relieves de estuco de esta fachada, además de favorecer enormemente su lectura, ya que:

Los motivos pintados se empleaban para articular las superficies y para resaltar planos y volúmenes. Los contrastes cromáticos [ayudan a guiar] los ojos de los espectadores a través de las composiciones. [...] en la época Barroca [...] la policromía refuerza el efecto emotivo y teatral de las composiciones" (Wrigth Carr 1988:144-148).

Por lo tanto, el estilo barroco de esta fachada, con la complejidad pictórica que requirió su ejecución, queda acentuado gracias a una intervención de reintegración que en su desarrollo técnico consideró, y asumió, dicha complejidad.

\section{Conclusiones}

Con su restauración, la fachada del templo de Santo Domingo revela uno de sus aspectos que había quedado cubierto tanto por intervenciones posteriores como por el deterioro, y la restablece como un elemento arquitectónico diseñado para narrar un relato, un discurso iconográfico, ideológico, desarrollado en el momento de su creación. Como resultado de este trabajo, hoy se aprecia el aspecto envejecido que tuvo la fachada en su primer y segundo momentos, en el que podemos identificar cada uno de los personajes representados, así como los elementos decorativos empleados para realzar esta fachada-altar. Los colores utilizados, sus diversas gradaciones o tonos, la forma en que se trabajaron, desvaneciéndolos o intensificándolos de acuerdo con el elemento en cuestión, no son producto de la febril imaginación de un grupo de trabajo, sino del conocimiento profundo de esta policromía a través del proceso descrito anteriormente. El comentario general de los pobladores de San Cristóbal de las Casas ante la obra restaurada ha sido, principalmente, de asombro ante la posibilidad actual de "ver" lo que antes no veían: los santos de los nichos, las águilas, los roleos de las columnas, los rombos o cruces empleados para decorar. Lo anterior confirma que ahora, a diferencia de lo que ocurría con anterioridad a la restauración, es posible leer la fachada. Ésta es ahora, para la gente de la localidad, un texto accesible, y muchos desean saber lo que representa cada elemento, su iconografía.

Lo anterior no evita, sin embargo, que algunos especialistas califiquen nuestra intervención como una falsificación. Otros señalan que debería considerarse una integración, más que como una reintegración de color. A pesar de la polémica, en 2006 el trabajo de restauración de la fachada obtuvo del Instituto Nacional de Antropología e Historia (INAH), el Premio Francisco de la Maza al mejor trabajo de restauración arquitectónica.

En lo personal considero que este tipo de intervenciones generarán siempre posturas paralelas o encontradas. La discusión permanece abierta.

\section{Agradecimientos}

Deseo agradecer a todas las personas e instituciones que participaron en la realización de este proyecto: arquitecto Hugo Gerardo Mendiguchía, restauradores María Elena Fernández Santoyo y J. Constantino Armendáriz Ballesteros, arquitecto Álvaro de la Cruz López Bravo, arqueólogo Andrés Brizuela Casimir, arquitectos Jorge B. Hernández y Vicente Guerrero, señor Pedro Cruz Porras Aguilar, restauradoras Ana Bertha Miramontes Mercado, Adriana Sanromán Peyrón y Hersalia Cantoral; químicos Mario Omar Fernández, Javier
Uribe y Farid Saab; frailes dominicos, presbítero Pablo Iribarrén y Roberto Álvarez, historiador Andrés Aubry, Archivo Parroquial de San Cristóbal de las Casas, antropólogo Julio César Domínguez, restaurador Germán Fraustro, maestra Olivia Lara, arquitectos Rudver Hernández Coronel, César Ramos Gurría y Luis E. Ochoa Morales; fotógrafo Octavio Moreno, escultor Eusebio Ortega, así como a los 21 jóvenes procedentes de las comunidades indígenas de los alrededores de San Cristóbal que nos asistieron.

\section{Referencias}

\section{Artigas H., Juan Benito}

1984 "San Cristóbal de las Casas y sus alrededores, esbozo de su arquitectura", en San Cristóbal de las Casas y sus alrededores, vol. II, Tuxtla Gutiérrez, Patronato Fray Bartolomé de Las Casas/SEC.

1991 La arquitectura de San Cristóbal de las Casas, México, Gobierno del Estado de Chiapas/UNAM.

1997 "Chiapas Monumental, (veintinueve monografías)", Universidad de Granada, Granada, España.

Aubry, Andrés

1990 San Cristóbal de las Casas. Su historia urbana, demográfica y monumental, 1528-1990, San Cristóbal de las Casas, Inaremac.

Brandi, Cesare

1968 Comentarios a Carta Internacional de Venecia, Guanajuato, Universidad de Guanajuato.

1990 Principios de teoría de la restauración, curso del ICCROM y la Facultad de Arquitectura de la Universidad de Roma, México, INAH (Textos Básicos y Manuales).

Díaz-Berrio, Salvador

1968 Comentarios a la Carta Internacional de Venecia, Guanajuato, Universidad de Guanajuato.

Doerner, Max

1989 Los materiales de pintura y su empleo en el arte, Barcelona, Reverté.

Flores Marini, Carlos

2004 "Reflexiones en torno a la Carta de Venecia 1964-2004-2044?", en "Conferencia Científica Internacio- 
nal", Budapest-Pecs-Hungría, 22-28 de mayo.

Gallego Roca, Francisco Javier

1996 Revestimiento y color en la arquitectura, Granada, Universidad de Granada.

Jokilehto, Jukka

2004 A History of Architectural Conservation, Oxford, Butterworth-Heinemann (Series in Conservation and $\mathrm{Mu}-$ seology).

López Bravo, Álvaro de la Cruz 2000 "Proyecto para la conservación de la fachada del templo de Santo Domingo en San Cristóbal de las Casas, Chiapas", mecanoescrito.
Markman, Sidney David 1993 Arquitectura y urbanización en el Chiapas colonial, Annabella Muñoa Rincón (trad.), Tuxtla Gutiérrez, Gobierno del Estado de Chiapas/ Consejo Estatal para el Fomento de la Investigación y Difusión de la Cultura/ DIF-Chiapas/ Instituto Chiapaneco de Cultura.

Monterrosa Prado, Mariano 1979 Manual de símbolos cristianos, México, Dirección de Estudios Históricos-INAH.

Orea Magaña, Haydeé 2007 "Informe de los trabajos de restauración de la fachada del templo de santo Domingo", mecanoescrito, INAH/Formas Constructivas, A. C./IMIP.

Orea Magaña, Haydeé y María Elena Fernández Santoyo

2006 "Proyecto para la restauración de la fachada del templo de Santo Domingo", mecanoescrito, México, INAH/ Formas Constructivas, A. C.

Wright Carr, David Charles 1998 "Los acabados de los monumentos novohispanos y la petrofilia al final del siglo XX", en La abolición del arte. XXI Coloquio Internacional de Historia del Arte, México, IIE-UnAM.

\section{Resumen}

Esta contribución analiza las consideraciones teóricas y practicas que llevaron al equipo que ejecutó los trabajos de restauración de la fachada del templo de Santo Domingo, en San Cristóbal de las Casas, Chiapas (México), a efectuar una intervención de reintegración de color a imitación de la original, cuyas implicaciones se abren a discusión.

\section{Palabras clave}

fachadas estucadas; reintegración de color; criterios; teoría de la restauración

\section{Abstract}

This article analyzes the theoretical and practical considerations with regard to the restoration of the façade of the Santo Domingo Church in San Cristóbal de las Casas, Chiapas (Mexico). In view of these, the team in charge of this work decided to undertake pictorial retouching in order to match the original color: the implications of this intervention are discussed here.

\section{Key words}

stucco facades; reintegration of color; criteria; restoration theory

Título en inglés: The Baroque Façade of Santo Domingo Temple, San Cristobal de las Casas (Mexico) and its pictorical retouching: a polemic intervention

Postulado/Submitted 3.05.2013

Aceptado/Accepted 21.08.2013 